\title{
Distance Education At The Graduate Level: A Viable Alternative
}

Brian M. Jones, Tennessee Technological University, USA Andrea Everard, University of Delaware, USA

Scott McCoy, The College of William \& Mary, USA

\begin{abstract}
This research extends a previous comparative study that looked at learning outcomes between traditional classroom and web-based education at the graduate level. That research (Jones and Everard, 2008) provided little evidence that there were significant differences between delivery methods. This research looks at employment status, household demographics, and family commitments and explores why these underlying factors do not affect outcomes between traditional classroom and web-based education at the graduate level. Results of this research provide evidence that for graduate level education, distance education is a practical and appropriate option.
\end{abstract}

Keywords: Distance Education; Graduate-Level Education; Information Technology; Instructional Technology; Web-Based Education

\section{INTRODUCTION}

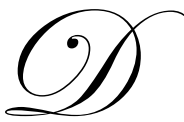

istance education, where teacher and student are physically separated but technologically connected, is an alternative educational model to the traditional classroom. Distance education is continually evolving. It is dynamic and non-static (Moore \& Kearsley, 2005) and has been broadly defined to include everything from correspondence courses and instructional videotapes to access via computer satellite and telecommunications technology (Picciano, 2001; Spooner, Jordan and Algozzine, 1999). Because geographical and temporal separation is no longer considered an obstacle to course delivery thanks to the Internet and other information technologies, an increasing number of individuals are now able to partake in this new educational opportunity.

This study is a follow-up to previous research conducted on the differences in learning outcomes between traditional and web-based course delivery for a required introductory Management Information Systems (MIS) course at the graduate level (Jones and Everard, 2008). Although, unexpectedly, no significant differences between traditional classroom and web-based education at the graduate level were found, there were still several characteristics of interest. Based on past research findings, we were concerned as to why differences were not evident. In this paper, we provide further insight as to why web-based education is a viable and useful alternative to traditional course delivery.

\section{PRIOR RESEARCH}

There has been an increase in online, or web-based, education programs with the introduction of the Internet and the abundance of educational applications (Natriello, 2005). Online learning management systems enable students to control when and where they learn (Lockhart, 2006). Distance education is often considered a more convenient alternative especially for non-traditional students given its ability to provide 'anytime', 'anywhere' education. Although not all types of students find online education attractive or suitable, often noted benefits include time and location flexibility (Glenn, 2001; Johnson et al., 2000; Rosenbaum, 2001), and having a sense of control over the learning environment (Petracchi, 2000). Also, students who are able to communicate well through writing, are self-motivated and self-disciplined, and are comfortable with using technology find online education appealing (Hiltz, 1995). 
The demand for degree programs, continuing professional education and workplace training delivered via online methods has been increasing by an average of ten percent annually since 1996 (Asunda, 2010). This, paired with the ever-increasing demands by employers that employees partake in lifelong learning and maintain and update their knowledge and skills, has resulted in an unprecedented expansion of online education programs (Lewis and Hedegaard, 1993). Distance education provides employees the opportunity to advance their knowledge, skills and abilities without sacrificing work, studies and family responsibilities (Asunda, 2010; Richardson, 2000). Lockhart (2006) noted that although most individuals partaking in distance education courses hold full-time jobs and many have families, they still wish to enhance their career and that distance education enables them to study off-campus and on their own time.

Although a meta-analysis on research studies on distance education conducted by Zhao, Lei, Yan, Lai and Tan (2005) found no differences in the aggregate data between traditional, face-to-face education and online education, they did find differences between individual studies. As with face-to-face education, variation exists in distance education programs. Some of these differences stem from the amount of interaction between students and instructors. An instructor who is involved in the delivery of the content of the course increases the students' opportunities to interact with the instructor. Studies show that distance education programs that include both synchronous and asynchronous interaction have the more positive outcomes. With the Internet it is becoming increasingly possible for students and instructors to take advantage of more cost-effective communication technologies and hence to interact and communicate (Cao et al., 2005). Moreover, Zhao et al.'s (2005) meta-analysis found that involvement with a 'live' instructor produced more positive outcomes than simply interacting with technology and that the most positive outcomes were found when a combination of technology and face-to-face was used. In fact, students enrolled in classes using such an approach, called blended or hybrid, have been found to earn better grades and higher levels of comprehension. In addition, such classes increased interactions and freed up classroom space. For distance education programs that are not able to include a face-to-face component, tools such as video conferencing can be used as a substitute (Levin et al., 2001).

\section{RESEARCH QUESTIONS}

As mentioned above, prior research has shown that there is little to no difference in learning outcomes between students studying via traditional classrooms on-campus and those utilizing distance education with little or no on-campus presence. In this paper, we first validate the findings from Jones and Everard (2008) and then we further investigate student characteristics. For example, due to the flexible nature of schedules for distance classes, is distance education better suited for those who have family obligations or significant work requirements? With that in mind we propose to explore the following:

Research Question 1: Do differences exist in learning outcomes at the graduate level, as measured by final exam grades and final course grades, between traditional classroom education and web-based learning?

Research Question 2: Can differences in learning outcomes at the graduate level be attributed to identifiable student attributes such as employment status and whether the student has children?

Research Question 3: Can differences in learning outcomes at the graduate level be attributed to identifiable educational mode (traditional classroom vs. web-based) characteristics?

\section{METHOD}

This research was conducted through a longitudinal field experiment. Categorical data was collected from all study participants including employment status, number of children that reside in the house, as well as age, gender, and computer efficacy in a naturally occurring educational environment. Final exam grades and overall course grades for students enrolled in the web-based classes and the traditional on-campus classes were compared to test for significant differences in performance across educational delivery methods. Age, gender, employment status, and family commitments were also tested for their effect on students' performance. 


\section{Participants}

The participants of this study were students at a public university located in the Southeastern section of the United States. All of the students were enrolled in a business master degree program and the course is the required Management Information Systems course. The students have the option of taking all classes on campus, all classes through distance education, or a combination of these two options.

\section{ANALYSIS AND RESULTS}

The statistical analysis was performed with SPSS version 16 . We first looked at the final grade between distance students and traditional students. Distance education students scored slightly lower (85.9795) than traditional students $(88.6062)(\mathrm{p}=.001)$. Although this difference is statistically significant, we do not consider it to be meaningful, as both scores represent the same letter grade for the course. Upon further investigation, the main reason for this difference became clear: the final exam score. In this particular course, the final exam is cumulative and heavily weighted. Much of the difference on the course grade can be attributed to a lower final exam score for distance education students. The final exam mean for distance students (87.4107) is statistically significantly different ( $\mathrm{p}=.003)$ than traditional students (90.5804).

When looking at other factors that can affect course performance, our results show that marital status has no impact on either final grade or final exam. Furthermore, having children has no impact on either final grade or final exam.

One of the reasons students choose distance education courses is flexibility, allowing students to work. When considering employment across both sets of students (distance and traditional), we found no impact on final grade, although there was a difference on exam score. When investigating this, we found that those working fulltime scored an average of 87.3519 on the final exam while those working half-time or less averaged 90.5259 on the final exam $(\mathrm{p}=.003)$.

As we evaluate other aspects of the course, such as projects and participation, we found no difference in course performance. In fact, the only area where distance and traditional students differed was in final exam grade. One could surmise that over the long run of the term those working full-time are able to manage fine but with one particular exam the work load might be too much.

\section{DISCUSSION AND CONCLUSIONS}

The results of this study are beneficial to both instructors and students. Given the above findings, it is apparent that traditional on-campus classes and distance off-campus classes are both appropriate and valid for graduate-level students. Given that the only difference found through our analysis is that traditional on-campus students seem to perform better on the final exam than distance education students, this can serve as evidence that a slight modification to web-based classes may be warranted.

For students considering continuing their education at the graduate level, this study has shown that traditional and web-based education are able to provide a comparable learning experience. For instructors, it is encouraging that both traditional and web-based education are viable alternatives to those wishing to further their education.

Considering that the participants in this study were students in a business school at the graduate level, it may not be appropriate to generalize our findings to other schools and colleges within a university. This however opens up the possibility of extending this research by looking at various schools and departments within universities and investigating whether web-based classes are an acceptable alternative to traditional on-campus courses in other disciplines. 


\section{AUTHOR INFORMATION}

Brian Jones is an Associate Professor of Management Information Systems in the College of Business at Tennessee Technological University. He received his $\mathrm{PhD}$ in Management Information Systems from the University of Pittsburgh. His research interests include international business applications (specifically Asia and the Pacific Rim), cross cultural issues in IS, human computer interaction, electronic commerce, and personal security and privacy issues with wireless systems. His work has been presented at several national and international conferences and appeared in leading academic journals including Communications of the ACM, Quality Management Journal, Journal of Global Information Technology Management and Communications of the AIS. E-mail: bjones@tntech.edu

Andrea Everard is an Associate Professor of Management Information Systems at the Lerner College of Business and Economics at the University of Delaware. She received her Ph.D. in management information systems from the University of Pittsburgh. Her research interests include human-computer interaction and cross-cultural issues in information systems. Journals in which her work appears include Journal of Management Information Systems, Communications of the ACM, Journal of Global Information Technology Management, and Information Systems Journal. E-mail: aeverard@udel.edu

Scott McCoy is an Associate Professor of Management Information Systems in The Mason School of Business at the College of William \& Mary. He earned his PhD in Information Systems from the University of Pittsburgh. His research in Cross Cultural Issues in IS, Human Computer Interaction (HCI), and Telecommunications Policy has been presented or published in many national and international conferences and journals such as Information Systems Research, Communications of the ACM, European Journal of Information Systems, Information Systems Journal, Journal of the Association for Information Systems, and Communications of the AIS. E-mail: ScottMcCoy@mason.wm.edu

\section{REFERENCES}

1. Asunda, Paul A. (2010) "Designing instruction for the distance learner," acteonline.org, 16-19.

2. Cao, J., Crews, J.M., Lin, M., Burgoon, J.K., and Nunamaker, J.F. Jr. (2005). Virtual Interaction for Effective E-learning. International Conference on Information Systems, Las Vegas, NV.

3. Glenn, Amy (2001) "A comparison of distance learning and traditional learning environments," ERIC Document Reproduction Service, ED457778.

4. Hiltz, Starr Roxanne "The Virtual Classroom: learning without limits via computer networks," Ablex Publishing Corp., NJ, 1995.

5. Jones, B. and Everard, A. (2008) "Web-Based vs. Traditional Education: Does Distance Education at the Graduate Level Deserve a Failing Grade?” AMCIS 2008 Proceedings, Toronto, Canada.

6. Levin, S.R., Levin, J.A., and Chandler, M. (2001) "Social and organizational factors in creating and maintaining effective online learning environments," paper presented at the Annual Meeting of the American Educational Research Association, Seattle, WA.

7. Lewis, C. and Hedegaard, T (1993) "Online education: Issues and some answers," T.H.E. Journal, 20:9, 68-71.

8. Lockhart, Jenny (2006) "Learning to fit in with real world - online and distance education", The Australian, April 26, 2006, 31.

9. Moore, Michael and Kearsley, Greg (2005) Distance Education: A Systems View, $2^{\text {nd }}$ edition, Thomas/Wadsworth.

10. Natriello, Gary (2005) "Modest changes, revolutionary possibilities: Distance learning and the future of education," Teachers College Record, 107:8, 1885-1904.

11. Petracchi, H. (2000). "Distance education: What do our students tell us?" Research on Social Work Practice, May 2000, 10:3, 362.

12. Picciano, A.G. (2001) Distance learning: Making connections across virtual space and time. Upper Saddle River, NJ: Merrill Prentice Hall.

13. Richardson, Jane (2000) "Remote study at your convenience," The Australian, March 22, 2000, 46. 
14. Rosenbaum, D.B., (2001) "E-learning beckons busy professionals: Electronic education offers anywhere, anytime flexibility... but not without problems, ENR, New York, 246:21, 38-42.

15. Spooner, F., Jordan, L., Algozzine, R. (1999) "Student ratings of instruction in distance learning and oncampus classes," Journal of Educational Research, 92:3, 132-140.

16. Zhao, Y., Lei, J., Yan, B., Lai, C. and Tan, H. (2005) "What makes the difference? A practical analysis of research on the effectiveness of distance education," Teachers College Board, 107:8, 1836-1884. 


\section{NOTES}

